\title{
Pengaruh Marketing Mix dan Service Quality Terhadap Consumer Satisfaction Transmart Carrefour Grand Kawanua dan Trans Studio Mini
}

\author{
Christine Natalia Wowiling \\ Riane Johnly Pio \\ Johnny A. F. Kalangi \\ Jurusan Manajemen Perusahaan, Program Studi Pengelolaan Sumberdaya Pembangunan \\ Fakultas Pascasarjana, Universitas Sam Ratulangi \\ wowilingchristine93@gmail.com
}

\begin{abstract}
This study aims to determine the extent the influence of classic marketing mix with variable product, price, place and promotion, on consumer satisfaction and the effect of service quality on consumer satisfaction. The populations in this study were Grand Kawanua Manado Transmart Carrefour customers, amounting to 1920 people, while the number of samples was 100 respondents. This study uses a quantitative approach with SEM-PLS analysis. The results of the study indicate that there is an effect of marketing mix on consumer satisfaction, and service quality influencing consumer satisfaction. To maintain consumer satisfaction in the era of very tight retail business competition, companies should continue to improve service quality to customers by paying attention to the elements of marketing mix such as determining reasonable and competitive prices, good product quality, and continuing promotion. The results of this study are expected to provide benefits for other researchers, and for practitioners in developing retail business marketing strategies.
\end{abstract}

Keywords: Marketing Mix, Service Quality, and Customer Satisfaction

\section{Pendahuluan}

Persaingan dalam dunia usaha dewasa ini begitu ketat seiring dengan bertambahnya jumlah pelaku usaha untuk memenuhi kebutuhan konsumen baik barang maupun jasa, pelaku usaha sering menghadapi tantangan untuk mendapatkan pangsa pasar yang mereka inginkan. Di lain pihak, konsumen cenderung semakin sensitif terhadap nilai yang ditawarkan setiap produk. Dalam kondisi pasar kompetitif pengetahuan preferensi dan kepuasan pelanggan adalah kunci sukses bagi perusahaan. Terlebih pada kondisi sekarang, pemasaran merupakan bagian yang penting dalam mempengaruhi persepsi konsumen. Untuk menghadapi persaingan yang semakin meningkat, perusahaan perlu memperhatikan dan menerapkan strategi pemasaran yang tepat agar konsumen mendapatkan kepuasan dan dapat berdampak berjangka panjang bagi perusahaan. Tentunya perusahaan harus melakukan pengembangan yang ber- 
kelanjutan terhadap strategi-strategi pemasarannya, untuk mendapatkan kepuasan dari konsumen. Pemenuhan kebutuhan dan keinginan konsumen membutuhkan konsep pemasaran yang disebut dengan bauran pemasaran (marketing mix). Kota Manado disematkan sebagai surga belanja di Indonesia Timur. Dikokohkan dengan kehadiran ritel - ritel yang sudah mempunyai nama yang dikenal di Indonesia. Lippo Group dengan Lippo Mall, Trans Retail dengan Transmart Carrefour, Matahari Putra Prima dengan Hypermart, hingga Hero Supermarket Group dengan Giant, telah membuka usaha di kota manado. Tanggapan dari masyarakat manado sendiri yang di rangkum oleh Manado post online. Contohnya tanggapan dari Kepala perwakilan Bank Indonesia (BI) Sulawesi Utara Soekowardojo melalui Deputi Direktur Buwono Budisantoso menyatakan, pesatnya perkembangan bisnis ritel di Bumi Nyiur Melambai, karena tingginya konsumsi masyarakat sehingga banyak investor di bidang ritel tidak ragu untuk menanamkan investasinya. "Daya konsumsi warga Sulut cukup baik bagi pertumbuhan bisnis ritel. Bisa di lihat, tenant fashion, aksesori maupun hand phone terus bertambah. Ini membuktikan daya beli masyarakat disini cukup baik bagi jalannya bisnis ini”.
Transmart adalah sebuah perusahaan ritel di Indonesia yang merupakan pemilik dari jaringan supermarket Carrefour serta Carrefour Express. Saat ini, Transmart merupakan salah satu anak perusahaan dari Trans Retail. Transmart sebuah perusahaan ritel di Indonesia yang merupakan pemilik dari jaringan supermarket Carrefour serta Carrefour Express. Saat ini, Transmart merupakan salah satu anak perusahaan dari Trans Retail. PT. Trans Retail hadir dengan konsep baru yaitu Transmart Carrefour dengan pembagian koridor belanja lebih rapi dan suasana belanja yang lebih nyaman, lebih luang dan lapang. Juga terdapat lounge pada area informasi yang dilengkapi dengan sofa sehingga membuat Anda nyaman saat menunggu antrian untuk dilayani.

Transmart sendiri tersebar di berbagai kota di Indonesia. Mulai dari Palembang, Pekanbaru, Bandar Lampung, Padang, Solok, Medan, Bengkulu, Cempaka putih, Cilandak, Kalimalang, Central Park Jakarta, Pasar Raya Blok M, Tanggerang, Depok, Bogor, Cimahi, Cipadung, Buah Batu, Soreang, Cirebon, Karawang, Semarang, Pekalongan, Solo, Purwokerto, Tegal, Maguwo, Surabaya, Kediri, Sidoarjo, Jember, Malang, Kubu Raya, Banjarmasin, Balikpapan, Makasar, Kupang, Mataram dan tentunya di Manado. 
Sebelum Transmart Carrefour Grand Kawanua, telah dibuka Transmart Starsquare yang berlokasi di Jl. Walter Monginsidi, Bahu, Malalayang, Manado. Karena mendapat respon yang baik dari masyarakat kota manado di buka Transmart Carrefour Grand Kawanua yang mempunyai keunggulan dari Transmart Starsquare yaitu tempat bermain keluarga yang menjadi pusat perhatian yaitu Trans Studio mini.

Transmart Carrefour Grand Kawanua tepatnya berada di J1 A.A Maramis, Kairagi Dua, Mapanget, Manado dan hadir dengan konsep 3 in 1. Berbelanja, bersantap, dan bermain berada dalam 1 kawasan gedung. Transmart Carrefour memiliki luas area 7.585 meter persegi. Sehingga pelanggan tidak perlu berpindah tempat lagi untuk berbelanja sambil menghabiskan waktu bersama keluarga. Transmart Carrefour Grand Kawanua menjadi pusat perbelanjaan masyarakat yang tinggal di sekitar dan menjadi tujuan pada hari libur.

Beragam fasilitas yang disediakan oleh Transmart Carrefour Grand Kawanua untuk pelanggan. Mulai dari tempat untuk membeli bahan makanan, makanan ringan, makanan siap saji, produk kecantikan, produk rumah tangga, alat belajar, tempat untuk beristirahat yang tidak perlu mengeluarkan uang untuk menunggu keluarga yang sedang berbelanja. Tentunya dengan banyak fasilitas yang tersedia, Transmart Carrefour Grand Kawanua harus memperhatikan apakah pelanggan sudah merasa puas dengan fasilitas yang ada atau belum. Pada hari tertentu atau hari ramai, banyak pelanggan yang datang berbelanja ataupun makan di Transmart Carrefour Grand Kawanua menandakan bahwa produk yang di tawarkan dan dijual dapat menarik perhatian pelanggan.

Transmart Carrefour Grand Kawanua dan Trans Studio Mini mendapat respon yang baik di masyarakat manado dan sekitar. Dalam Google Review atau Ulasan yang di rangkum google banyaknya masyarakat kota manado yang sudah berkunjung di Transmart Carrefour Grand Kawanua dan Trans Studio Mini, dapat dilihat pada table berikut:

\begin{tabular}{ccc}
\hline \multirow{2}{*}{ No } & \multicolumn{2}{c}{2018} \\
\cline { 2 - 3 } & Bulan & $\begin{array}{c}\text { Jumlah } \\
\text { Customer }\end{array}$ \\
\hline 1. & Januari & 117 \\
\hline 2. & Ferbruari & 71 \\
\hline 3. & Maret & 91 \\
\hline 4. & April & 127 \\
\hline 5. & Mei & 205 \\
\hline 6. & Juni & 239 \\
\hline 7. & Juli & 222 \\
\hline 8. & Agustus & 198 \\
\hline 9. & September & 163 \\
\hline 10. & Oktober & 190 \\
\hline 11. & November & 157 \\
\hline 12. & Desember & 140 \\
\hline
\end{tabular}

\section{Tinjauan Pustaka}

Pengertian marketing mix menurut Menurut Kotler dan Armstrong (1997) 
adalah perangkat alat pemasaran taktis yang dapat dikendalikan, produk, harga, distribusi, dan promosi yang dipadukan oleh perusahaan untuk menghasilkan respons yang diinginkan dalam target market.

Menurut Buchari Alma (2005), pengertian marketing mix adalah strategi mengkombinasikan kegiatan-kegiatan marketing, agar tercipta kombinasi maksimal sehingga akan muncul hasil paling memuaskan.

Menurut Sumarni dan Soeprihanto (2010), Produk adalah setiap apa saja yang bisa ditawarkan di pasar untuk mendapatkan perhatian, permintaan, pemakaian atau konsumsi yang dapat memenuhi keinginan atau kebutuhan. Produk tidak hanya selalu berupa barang tetapi bisa juga berupa jasa ataupun gabungan dari keduanya (barang dan jasa). Transmart Carrefour Grand Kawanua menyediakan berbagai macam produk mulai dari pakaian, berbagai macam peralatan, produk kecantikan, makanan dan wahana permainan. Harga (price) menggambarkan besarnya rupiah yang harus dikeluarkan konsumen untuk memperoleh satu buah produk dan hendaknya harga akan dapat terjangkau oleh konsumen. Menurut Sumarni dan Soeprihanto (2010) harga adalah, Jumlah uang yang dibutuhkan untuk mendapatkan sejumlah kombinasi dari barang beserta pelayanannya". Setelah produk yang diproduksi siap untuk dipasarkan, maka perusahaan akan menentukan harga dari produk tersebut. Harga yang ditawarkan oleh Transmart Carrefour Grand Kawanua bervariasi sesuai dengan produk yang dijual. Tempat (place) tempat dimana produk tersedia dalam sejumlah saluran distribusi dan outlet yang memungkinkan konsumen dapat dengan mudah memperoleh suatu produk. Tempat dalam marketing mix biasa disebut dengan saluran distribusi, saluran dimana produk tersebut sampai kepada konsumen. Promosi (promotion) menggambarkan berbagai macam cara yang ditempuh perusahaan dalam rangka menjual produk ke konsumen. Menurut Tjiptono (2008), pada hakikatnya promosi adalah suatu bentuk komunikasi pemasaran. Yang dimaksud dengan komunikasi pemasaran adalah aktivitas pemasaran yang berusaha menyebarkan informasi, mempengaruhi/ membujuk, dan/atau mengingatkan pasar sasaran atas perusahaan dan produknya agar bersedia menerima, membeli, dan loyal pada produk yang ditawarkan perusahaan yang bersangkutan. Promosi yang dilakukan oleh Transmart Carrefour Grand Kawanua adalah dengan media elektronik dan media cetak. 
Menurut Fitzsimmons bersaudara dalam Sulastiyono (2011) menjelaskan bahwa kualitas pelayanan adalah sesuatu yang kompleks, dan tamu akan menilai kualitas pelayanan melalui lima prinsip dimensi pelayanan sebagai ukurannya, yaitu sebagai berikut:

Reliabilitas (Reliability), adalah kemampuan untuk memberikan secara tepat dan benar jenis pelayanan yang telah dijanjikan kepada tamu.

Responsif (Responsiveness), yaitu kesadaran atau keinginan untuk cepat bertindak membantu tamu dan memberikan pelayanan yang tepat waktu.

Kepastian/jaminan

(Assurance), adalah pengetahuan dan kesopan santunan serta kepercayaan diri para pegawai. Dimensi assurance memiliki ciri-ciri: kompetensi untuk memberikan pelayanan, sopan dan memiliki sifat respek terhadap tamu.

Empati (Empathy), memberikan perhatian individu tamu secara khusus. Dimensi empathy ini memiliki ciri-ciri: kemauan untuk melakukan pendekatan, memberikan perlindungan dan usaha untuk mengerti keinginan, kebutuhan dan perasaan tamu.

Nyata (Tangibles), yaitu sesuatu yang nampak atau yang nyata, yaitu: penampilan para pegawai, dan fasilitas-fasilitas fisik lainnya seperti peralatan dan perlengkapan yang menunjang pelaksanaan pelayanan.

Menurut Gerson (2002) kepuasan pelanggan adalah persepsi pelanggan bahwa harapan telah terpenuhi atau terlampaui, jika pelanggan berharap barang tersebut akan befungsi dengan baik. Jika tidak pelanggan akan kecewa. Maka perusahaan harus menemukan cara untuk mengatasi masalah tersebut sehingga pelanggan bisa menjadi puas. Pelanggan yang puas akan melakukan bisnis lebih banyak dan lebih sering dengan suatu perusahaan, sehingga keuntungan perusahaan semakin besar.

\section{Kerangka Pemikiran}

Berdasarkan pada rumusan masalah yang telah diuraikan mengenai pengaruh produk, harga, promosi, tempat dan pelayanan maka kerangka pemikiran teoritis yang diajukan dalam penelitian ini digambarkan sebagi berikut:

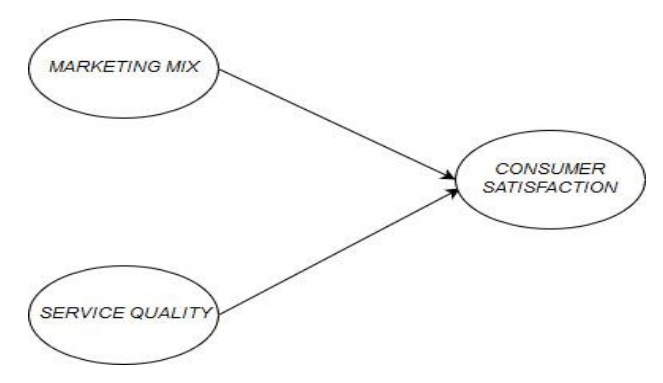

Kerangka pikir merupakan arah penelitian yang akan dilakukan, berdasarkan kerangka pikir tersebut maka 
akan dilakukan penelitian tiap variabel $\mathrm{x}$ terhadap y dan variabel mana yang mendominasi pengaruh tingkat kepuasan konsumen Transmart Carrefour Grand Kawanua dan Trans Studio Mini.

\section{Metode Penelitian}

Penulis menggunakan metode penelitan kuantitatif pada penelitian yang dilakukan di Transmart Carrefour Grand Kawanua dan Trans Studio Mini tepatnya berada di Jl A.A Maramis, Kairagi Dua, Mapanget, Manado, Sulawesi Utara. Populasi dari penelitian ini adalah seluruh pelanggan/consumer Transmart Carrefour Grand Kawanua dan Trans Studio Mini, dengan jumlah populasi 1920 consumer. Teknik yang digunakan dalam menentukan sampel adalah rumus Lameshow. Bila populasi besar dan penelitian tidak mungkin mempelajari semua yang ada pada populasi, misalnya keterbatasan dana, tenaga dan waktu maka penelitian dapat menggunakan sampel yang diambil dari populasi itu (Sugiyono, 2008). Populasi dalam penelitian ini sangat besar jumlahnya dan untuk menentukan jumlah sampel menggunakan rumus Lameshow et. al (1997).

$$
n=\frac{z^{2}{ }_{1-a / 2} P(1-p)}{d^{2}}
$$

Dimana sampel yang didapat dengan menggunakan rumus tersebut sebanyak 96 dibulatkan menjdi 100 orang. Teknik pengumpulan data menggunakan bantuan kuesioner. Penelitian ini akan menggunakan analisis Partial Least Square (PLS) dengan bantuan software SmartPLS untuk mengetahui pengaruh antara variabel marketing mix dengan consumer satisfaction, variabel service quality dengan consumer satisfaction Langkah-langkah yang akan ditempuh dalam analisis data setelah kuesioner ditabulasi adalah: 1) Membuat tabel distribusi variabel marketing mix. 2) Membuat tabel distribusi variabel service quality. 3) Membuat tabel distribusi variabel consumer satisfaction. 4) Mengkonstruksi diagram path. 5) Proses komputasi.

\section{Hasil Penelitian}

Hasil yang didapatkan sesuai analisis uji validitas dengan menggunakan smartPLS menyatakan bahwa semua pernyataan pada kuesioner diketahui bahwa variabel X1 (Marketing Mix), X2 (Service Quality), Y (Consumer Satisfaction), Tabel dibawah ini memperlihatkan bahwa tidak ada nilai yang lebih besar dari angka paling kanan setiap barisnya. Dengan demikian dapat disimpulkan bahwa semua item telah memenuhi validitas. 


\begin{tabular}{cccc}
\hline & $\mathrm{X} 1$ & $\mathrm{X} 2$ & $\mathrm{Y}$ \\
\hline $\mathrm{X} 1$ & 0.724 & & \\
\hline $\mathrm{X} 2$ & 0.818 & 0.895 & \\
\hline$Y$ & 0.813 & 0.820 & 0.871 \\
\hline
\end{tabular}

Kemudian untuk uji realibilitas, nilai Alpha Cronbach ketiga variabel telah melebihi nilai 0.7 , dengan demikian dapat disimpulkan bahwa instrumen telah memenuhi persyaratan valid dan reliabel, sehingga data yang diperoleh dari kuesioner dapat digunakan untuk analisis data pada tahap selanjutnya.

\section{Pengaruh Marketing Mix (X1)} terhadap Consumer Satisfaction (Y), diperoleh koefisien struktural sebesar 0.428 dan $\mathrm{P}$-value $<0.001$. Karena $\mathrm{P}$-value $<0.05$, mengindikasikan bahwa signifikannya pengaruh antara Marketing Mix (X1) terhadap Consumer Satisfaction (Y). Artinya semakin tingginya Marketing Mix (X1), akan mempengaruhi tinggi rendahnya Consumer Satisfaction (Y). Dengan demikian, hipotesis 1 penelitian ini diterima.

Hasil penelitian ini sejalan dengan hasil penelitian Mustawadjuhaefa (2017) menyatakan bahwa marketing mix berpengaruh positif signifikan terhadap customer satisfaction, Penelitiannya mengatakan marketing mix yang baik akan meningkatkan customer satisfaction, dan sejalan dengan penelitian Sarker et al (2012) dimana marketing mix memiliki dampak positif dan signifikan terhadap customer satisfaction, di penelitiannya menyatakan adanya dampak positif signifikan marketing mix terhadap customer satisfaction.

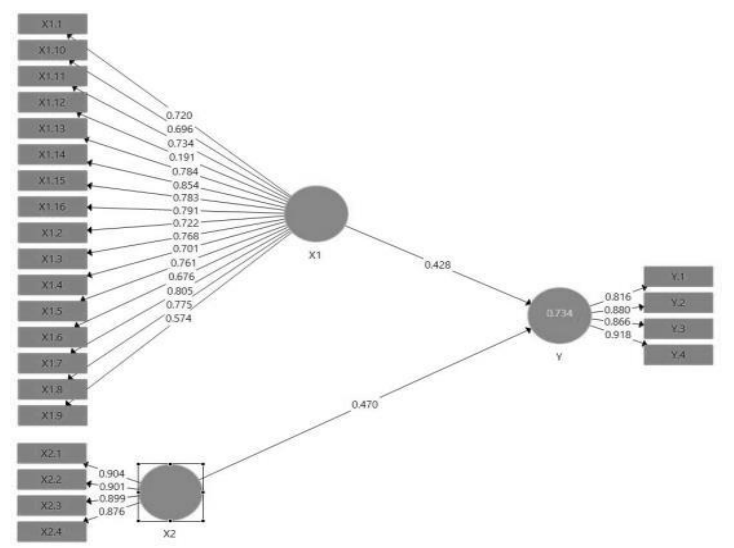

Pengaruh Service Quality (X2) terhadap Consumer Satisfaction (Y), diperoleh koefisien struktural sebesar 0.470 dan $\mathrm{P}$-value $<0.001$. Karena $\mathrm{P}$-value $<0.05$, mengindikasikan bahwa signifikannya pengaruh antara Service Quality (X2) terhadap Consumer Satisfaction (Y). Artinya semakin tingginya Service Quality (X2), akan mempengaruhi tinggi rendahnya Consumer Satisfaction (Y). Dengan demikian, hipotesis 2 penelitian ini diterima. Hasil penelitian ini sejalan dengan pendapat Lupiyoadi (2006), yang menyatakan bahwa salah satu cara meningkatkan kepuasan kepada para pelanggan adalah dengan memberikan produk atau jasa yang berkualitas. Hal senada dengan penelitian R. J. Pio, H. J. 
Sumampow, Triyono (2008), dengan penelitian berjudul Pengaruh Kualitas Layanan Terhadap Kepuasan Pelanggan PT. Angkasa Pura I Bandar Udara Sam Ratulangi Manado dimana menyatakan ada pengaruh keramahan layanan terhadap kepuasan pelanggan pengguna jasa bandar udara Sam Ratulangi Manado.

\section{Kesimpulan}

Berdasarkan hasil analisis yang telah diuraikan pada bab sebelumnya, dalam penelitian ini dapat disimpulkan hal-hal berikut ini:

Terdapat pengaruh yang signifikan antara Marketing Mix terhadap Consumer Satisfaction. Dengan demikian, tinggi rendahnya Consumer Satisfaction dipengaruhi oleh Marketing Mix. Adanya pengaruh yang signifikan antara variabel product, price, place, dan promotion dengan variabel consumer satisfaction. Tinggi rendahnya consumer satisfaction dipengaruhi oleh marketing mix yang dalam penelitian ini meliputi classic marketing mix dengan 4P (Product, Price, Place, dan Promotion).

Terdapat pengaruh yang signifikan antara Service Quality terhadap Consumer Satisfaction. Dengan demikian, tinggi rendahnya Consumer Satisfaction dipengaruhi oleh Service Quality.

\section{Saran}

Berdasarkan atas hasil penelitian, maka berikut beberapa saran yang dapat direkomendasikan:

Perlunya ditingkatkan strategi Marketing Mix dari Transmart Carrefour Grand Kawanua dan Trans Studio Mini dengan cara memperhatikan strategi dari Marketing Mix yang masih kurang secara konsisten dan berkesinambungan, hal ini bisa memudahkan, dan meningkatkan tingkat kepuasan Consumer dari Transmart Carrefour dan Trans Studio Mini dimulai dari mempersiapkan, dan mengecek keterbatasan stock produk, kualitas dari produk yang dipasarkan. Menyesuaikan harga dari produk yang dipasarkan berdasarkan kualitas produk. Memperhatikan tempat penempatan produk-produk untuk memudahkan consumer, dan memberi promosi-promosi untuk menarik consumer.

Perlunya ditingkatkan lagi Service Quality dari karyawan Transmart Carrefour Grand Kawanua dan Trans Studio Mini untuk mempertahankan tanggapan yang baik dari Consumer Transmart Carrefour Grand Kawanua dan Trans Studio Mini. Memberikan karyawan yang bekerja dengan baik hadiah / reward, memberikan pengarahan kepada karyawan bagaimana cara untuk menghadapi atau berkomunikasi yang baik dengan consumer melalui 
training karena pelanggan ingin merasa nyaman pada saat berbelanja atau melihat dan mencari suatu produk mengingat permintaan Consumer bisa berubah sewaktu-waktu dan setiap consumer mempunyai perilaku yang berbeda-beda.

\section{Daftar Pustaka}

Buchari, A. 2005. Manajemen Pemasaran dan Pemasaran Jasa. Cetakan ke-7. Alfabeta, Bandung.

Gerson, R. F. 2002. Mengukur Kepuasan Pelanggan. Cetakan kedua, Jakarta: PPM.

Kotler, P. dan Amstrong G. 1997. DasarDasar Pemasaran. Jilid I, Jakarta: Prenballindo.

Pio R. J, Sumampow H. J, Triyono (2008) Pengaruh Kualitas Layanan terhadap Kepuasan Pelanggan pada PT. Angkasa Pura I Bandar udara Sam Ratulangi Manado. Journal of Business and Management, Eksekutif. Volume 5, nomor 1. Hal 38-55.

Sarker, S et al. 2006. Natural Product Isolation. Second Edition. Humana Press Inc. New Jersey.

Sugiyono. 2008. Metode Penelitian Kuantitatif, Kualitatif, dan $R \& D$. CV Alfabeta. Bandung.

Sumarni, Murti dan John Soeprihanto. 2010. Pengantar Bisnis (Dasar-dasar Ekonomi Perusahaan). Edisi ke 5. Yogyakarta: Liberty Yogyakrta

Tjiptono, F. 2008. Strategi Pemasaran. CV. Andi Offset. Yogyakarta. 